\title{
Accuracy of the Spot Sign on Computed Tomography Angiography as a Predictor of Haematoma Enlargement after Acute Spontaneous Intracerebral Haemorrhage: A Systematic Review
}

\author{
Angela Del Giudice ${ }^{a, b} \quad$ Delia D'Amico $^{c} \quad$ Jan Sobesky ${ }^{a} \quad$ lan Wellwood ${ }^{a}$ \\ ${ }^{a}$ Centre for Stroke Research Berlin, Charité-Universitaetsmedizin, and ${ }^{b}$ Department of Neurology, \\ Vivantes Klinikum Neukoelln, Berlin, Germany; ${ }^{C}$ Department of Neurosciences, S. Maria della Misericordia \\ University Hospital, Udine, Italy
}

\section{Key Words}

CT angiography $\cdot$ Haematoma enlargement $\cdot$ Intracerebral haemorrhage · Prognosis · Spontaneous intracerebral haemorrhage $\cdot$ Spot sign

\begin{abstract}
Background: A common early complication of intracerebral haemorrhage $(\mathrm{ICH})$ is haematoma enlargement $(\mathrm{HE})$, a strong independent predictor of a poor outcome. Therapeutic options to limit haematoma progression are currently scarce. Haemostatic therapy may be effective in patients with $\mathrm{ICH}$, but it carries the risk of thromboembolic events in unselected patients. Accurate patient selection would, therefore, be of key importance for delivering potentially successful therapeutic strategies. Currently, there is no gold standard to accurately predict $\mathrm{HE}$. The presence of contrast extravasation within the haematoma on computed tomography angiography (CTA), the 'spot sign', has been reported in several studies and seems a particularly promising marker but lacks a standardised evaluation so far. Summary: We conducted a systematic review of published data to address the research question: In adults with acute spontaneous $I C H$, how accurately does the spot sign predict $\mathrm{HE}$ on follow-up
\end{abstract}

imaging and thus poor functional outcome or mortality? We searched PubMed and Embase databases (from 1980 to May 2012), using a highly sensitive search strategy and including all studies involving adult patients with spontaneous $\mathrm{ICH}$ evaluated with CTA and follow-up CT scans, reporting any measure of clinical outcome, and reporting or allowing calculation of accuracy measures of the spot sign in predicting $\mathrm{HE}$ and clinical outcome. Baseline characteristics, accuracy measures and effect measures, as well as bias assessment, were reported according to PRISMA recommendations. The quality of the studies was appraised using an adapted version of the REMARK reporting recommendations. From 259 potentially relevant studies, we finally selected 6 studies ( 1 of them was a multicentre cohort study) covering a total of 709 patients. Studies varied substantially in terms of size, methodological quality, definitions of terms, outcomes selected and results. In particular, definition of the spot sign was not consistent in all studies. Furthermore, the only outcome measure consistently available was $\mathrm{HE}$, while definitions and analyses of clinical outcomes seemed not adequate. Lastly, the choice of candidate variables for univariate and multivariate analyses did not include all determinants of $\mathrm{HE}$ and poor functional outcome. High heterogeneity was demonstrated ( $I^{2}: 94 \%$ for $\mathrm{HE}$ ) with substantial potential of

\section{KARGER}

E-Mail karger@karger.com

www.karger.com/ced
(C) 2014 S. Karger AG, Basel

$1015-9770 / 14 / 0374-0268 \$ 39.50 / 0$
Angela Del Giudice

Department of Neurology, Vivantes Klinikum Neukoelln

Rudower Strasse 48

DE-12351 Berlin (Germany)

E-Mail angeladelgiudice@gmail.com 
bias. Key Messages: Studies of the spot sign are diverse and therefore complex to interpret. Our research question could not be answered due to heterogeneity and potential of bias in the selected studies. Further appropriately powered studies using standardised definitions and taking all predictors of $\mathrm{HE}$ and poor clinical outcome into account are required for a proper clinical implementation. @ $\quad 2014$ S. Karger AG, Basel

\section{Introduction}

Intracerebral haemorrhage (ICH) accounts for approximately $10-30 \%$ of all strokes among high- and low/ middle-income countries, respectively [1], and has an overall ICH case fatality at 1 month of about $40 \%$ (range 13-61\%) in almost all regions [2].

A common early complication of ICH is haematoma enlargement (HE), which affects about $30 \%$ of patients presenting within $3 \mathrm{~h}$ of onset and up to $70 \%$ within $24 \mathrm{~h}$ of onset, and is a strong independent predictor of a poor outcome [3-5]. Therefore, early HE identification could help to stratify patients on the basis of their risk profile and thus guide clinicians' decisions on treatment [6]. Therapeutic options to limit haematoma progression are currently scarce. Besides blood pressure control, haemostatic therapy, particularly with recombinant factor VIIa, may be effective in accurately selected ICH patients [5].

A promising marker of $\mathrm{HE}$ is the presence of contrast extravasation within the haematoma on computed tomography angiography (CTA). Firstly described in 1999 $[7,8]$, the presence of enhancing foci of contrast extravasation or the 'spot sign' in the setting of actively bleeding $\mathrm{ICH}$ has been demonstrated in about a third of the patients in several single-centre studies $[9,10]$.

Recently, a multicentre prospective observational cohort study confirmed previous findings [11], but the sensitivity of the spot sign in predicting HE was relatively low and not all predictors of $\mathrm{HE}$ or poor functional outcome were included in the analysis [12].

Nevertheless, the spot sign is being used in ongoing clinical trials (e.g. the Spot Sign for Predicting and Treating ICH Growth Study, STOP-IT Study - ClinicalTrials.gov NCT00810888, the 'Spot Sign' Selection of Intracerebral Haemorrhage to Guide Haemostatic Therapy, SPOTLIGHT Study - ClinicalTrials.gov NCT01359202, and the Spot Sign and Tranexamic Acid on Preventing ICH Growth - Australasia Trial, STOPAUST - ClinicalTrials.gov NCT01702636) as a tool to stratify patients for treatment.
To date, results from individual studies have not been systematically summarised. Therefore, our study aimed to answer the research question: In the adult population with acute spontaneous ICH, how accurately does the presence of contrast extravasation on CTA, the spot sign, predict $\mathrm{HE}$ on follow-up imaging and subsequent poor outcome [defined as death or long-term disability - the latter measured by the National Institutes of Health Stroke Scale (NIHSS) [13] and/or modified Rankin Scale (mRS)] [14]?

\section{Methods}

A systematic review of the literature was conducted using secondary data analysis of published studies, and, therefore, ethical approval and data protection permissions were not required.

All available studies (including case series, cohort, case-control and randomised trials) were included if the following inclusion criteria were met: patients $\geq 18$ years of age with confirmed spontaneous ICH evaluated with CTA and follow-up CT scans, studies reporting any measure of clinical outcome (NIHSS, mRS or death), and reporting or allowing calculation of sensitivity and specificity (with confidence intervals, CI), positive and negative predictive values, positive and negative likelihood ratios, prevalence and accuracy of the 'spot sign' in predicting haematoma growth and clinical outcome. Studies including patients with secondary ICH and case reports were excluded.

A highly sensitive search strategy with different combinations of appropriate key words was developed (see online suppl. appen$\operatorname{dix} 1$; for all online suppl. material, see www.karger.com/ doi/10.1159/000360754). Two reviewers (A.D.G. and D.D.A.) independently searched PubMed and Embase from 1980 (when CT became widely available) to the end of May 2012 (as late as project resources permitted). Reference lists, related articles and citation lists of each of the papers identified in the initial searches were screened in order to identify any further relevant papers. Grey literature (conference abstracts, letters and editorials) was reviewed separately; however, due to resource constraints, full quality assessment was not conducted on this material. Where a duplicate publication was identified, the main report or the most informative cohort was included in the review.

Initial screening of study titles excluded non-relevant topics and remaining studies were further screened by reading abstracts. The final eligible studies and any supplementary material were read in full.

A quality assessment tool and a data extraction form were produced and piloted. Data were independently extracted using this form (see online suppl. appendix 2), with disagreements during this process resolved with a third referee (I.W.). No assumptions were made to derive data. No additional data were obtained from the investigators.

There are currently no guidelines for quality assessment of prognostic studies [15]. Therefore, a novel quality assessment tool, which was based on items in the REMARK recommendations for prognostic tumour markers [16], was developed. 


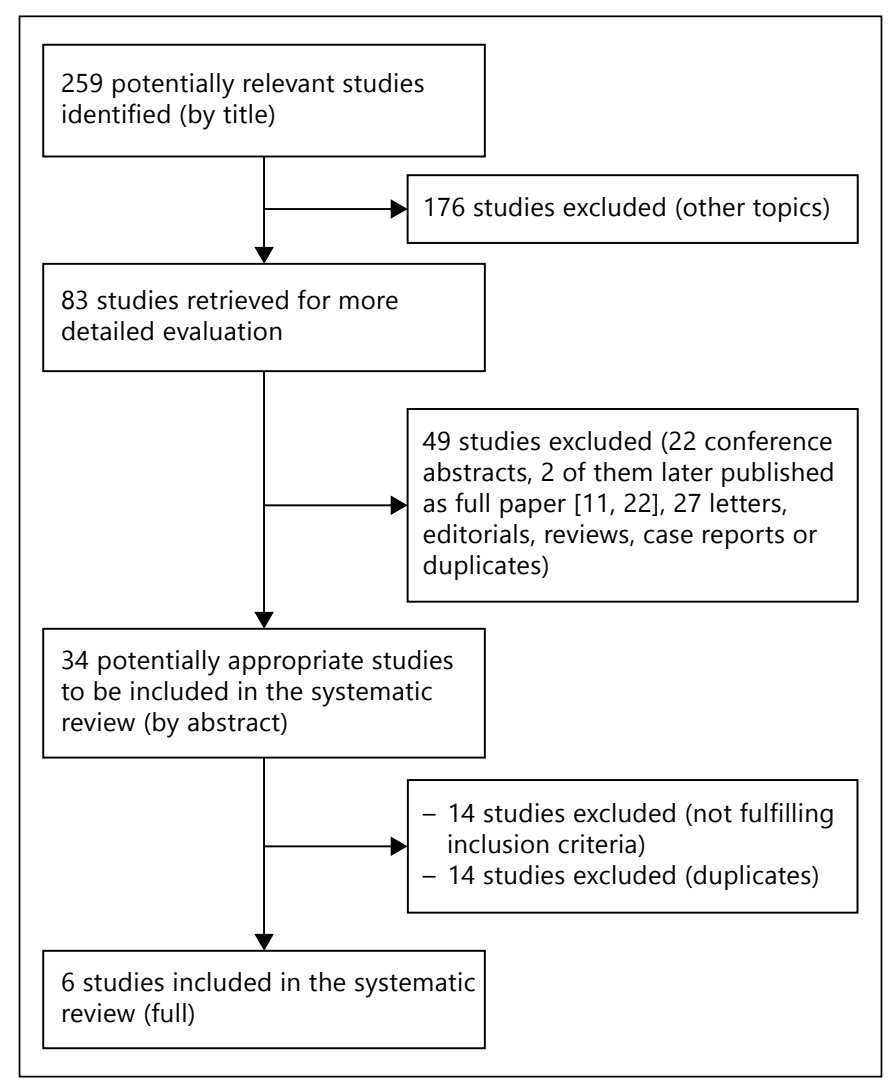

Fig. 1. Literature search.

Where results were not reported directly or were incomplete (for instance without CI), these were calculated, where possible, based on data provided in the paper. Data were managed using Excel software and analysed using Stata 10.0 statistical software.

For the radiological outcome, the only outcome consistently available, a funnel plot was drawn to estimate the risk of publication bias. Formal tests for funnel plot asymmetry were not carried out given the few studies included [17]. An exploratory test for heterogeneity ( $\mathrm{I}^{2}$ statistics) was performed [18].

\section{Results}

Figure 1 depicts the study selection. Of 34 potentially eligible studies, 14 did not fulfil our inclusion criteria (table 1; references partly in online suppl. appendix 3 ). The remaining 14 studies which were excluded were duplicates. Six studies were included in this review [9-11, 21-23].

Table 2 provides the main characteristics of the selected studies. The median recruitment period was 2 years (interquartile range 1-4; for the years from 2004 to 2010) and the total number of patients included was $709($ median $=107)$.
Table 1. Studies not fulfilling the inclusion criteria of the present systematic review

\begin{tabular}{|c|c|}
\hline Authors & Reason(s) for exclusion \\
\hline Becker et al. [7] & No follow-up CT \\
\hline $\begin{array}{l}\text { Brouwers et al. } \\
{[2, \text { online }]}\end{array}$ & $\begin{array}{l}\text { Follow-up CT available only for subgroup } \\
\text { analysis ( } 228 \text { patients) } \\
\text { Accuracy measure for radiological and } \\
\text { clinical outcome not available/calculable }\end{array}$ \\
\hline $\begin{array}{l}\text { Delgado et al. } \\
{[3, \text { online }]}\end{array}$ & $\begin{array}{l}\text { Age criterion not fulfilled (range } 6-94 \text { years) } \\
\text { No data on clinical outcome }\end{array}$ \\
\hline Delgado et al. [24] & Age criterion not fulfilled (range $8-94$ years) \\
\hline d'Esterre et al. [42] & $\begin{array}{l}\text { Definition of ICH not specified } \\
\text { Accuracy measures not available/calculable }\end{array}$ \\
\hline $\begin{array}{l}\text { Ederies et al. } \\
{[6, \text { online }]}\end{array}$ & $\begin{array}{l}\text { Definition of ICH not specified } \\
\text { Accuracy measures for clinical outcome not } \\
\text { available/calculable }\end{array}$ \\
\hline $\begin{array}{l}\text { Evans et al. } \\
{[7, \text { online }]}\end{array}$ & $\begin{array}{l}\text { Accuracy measures for clinical outcome not } \\
\text { available/calculable }\end{array}$ \\
\hline Gazzola et al. [20] & $\begin{array}{l}\text { Accuracy measures for radiological and } \\
\text { clinical outcome not available/calculable }\end{array}$ \\
\hline Hallevi et al. [19] & $\begin{array}{l}\text { Age not specified } \\
\text { Accuracy measures for clinical outcome not } \\
\text { available/calculable }\end{array}$ \\
\hline $\begin{array}{l}\text { Kim et al. } \\
{[10, \text { online }]}\end{array}$ & $\begin{array}{l}\text { Accuracy measures for radiological outcome } \\
\text { not available/calculable }\end{array}$ \\
\hline Murai et al. [8] & $\begin{array}{l}\text { Definition of ICH not specified } \\
\text { Data on clinical outcome not available }\end{array}$ \\
\hline $\begin{array}{l}\text { Romero et al. } \\
{[12, \text { online }]}\end{array}$ & $\begin{array}{l}\text { Accuracy measures for radiological and } \\
\text { clinical outcome not available/calculable }\end{array}$ \\
\hline $\begin{array}{l}\text { Thompson et al. } \\
{[13 \text {, online }]}\end{array}$ & $\begin{array}{l}\text { Accuracy measures for radiological and } \\
\text { clinical outcome not available/calculable }\end{array}$ \\
\hline $\begin{array}{l}\text { Wang et al. } \\
{[14, \text { online }]}\end{array}$ & $\begin{array}{l}\text { Definition of ICH not specified } \\
\text { Accuracy measures for clinical outcome not } \\
\text { available/calculable }\end{array}$ \\
\hline
\end{tabular}

Data on Glasgow Coma Scale and NIHSS score were available for all studies, except for the study by Wada et al. [9]. Among the baseline characteristics reported to be associated with HE and poor outcome, use of oral anticoagulants or anti-platelet agents, blood pressure values and glucose values on admission were always considered. Furthermore, Demchuk et al. [11], Goldstein et al. [10] and Li et al. [22] also collected data on previous stroke.

Quality was assessed according to themes in the adapted REMARK form. All the selected papers but 1 [10] re- 
Table 2. Main characteristics of the studies selected

\begin{tabular}{|c|c|c|c|c|}
\hline Authors & $\begin{array}{l}\text { Publication, } \\
\text { year }\end{array}$ & Country & $\begin{array}{l}\text { Population, } \\
\mathrm{n}\end{array}$ & $\begin{array}{l}\text { Median or mean age } \\
(\text { range } / \pm S D)\end{array}$ \\
\hline Demchuk et al. [11] & 2012 & $\begin{array}{l}\text { Canada, Spain, Germany, } \\
\text { Poland, India, USA }\end{array}$ & 228 & $\begin{array}{l}\text { Spot +: } 73(38-90) \\
\text { Spot -: } 70(21-100)\end{array}$ \\
\hline Goldstein et al. [10] & 2007 & USA & 104 & $\begin{array}{l}\text { Spot +: } 74(69-81) \\
\text { Spot -: } 72(63-78)\end{array}$ \\
\hline Park et al. [21] & 2010 & South Korea & 110 & $\begin{array}{l}\text { Overall: } 62(33-88) \\
\text { Spot }+: 61( \pm 16) \\
\text { Spot }-: 60( \pm 14.1)\end{array}$ \\
\hline Rodriguez-Luna et al. [23] & 2012 & Spain & $\begin{array}{l}89 \text { with CTA/ } \\
133 \text { total }\end{array}$ & $\begin{array}{l}\text { Overall (for all } 133 \text { patients): } \\
71.7( \pm 11.8)\end{array}$ \\
\hline
\end{tabular}

ported prospective cohort studies enrolling mainly consecutive patients (they did not specify the sampling strategy). In the study by Goldstein et al. [10], data were collected retrospectively and reviewed from an ongoing prospective cohort study on outcome after ICH. Only the study by Demchuk et al. [11] involved multiple centres. All studies reported defined inclusion and exclusion criteria and the enrolment period. Patients were followed up for 3 months in all studies except 1 study [10], which only reported in-hospital mortality. A sample size calculation was provided in 2 studies $[10,11]$ on the basis of the primary outcome (haematoma growth). Candidate variables, characteristics potentially associated with the outcome variable and to be included in univariate analyses, were always listed. Spot sign/contrast extravasation and pre-specified radiological and clinical outcomes were fully defined in all but 1 paper [23] and varied considerably across studies (table 3). Furthermore, Demchuk et al. [11] reported that the definition of the spot sign was not established at the beginning of the study, although not affecting their inter-rater agreement $(\mathrm{k}=0.72)$.

Assessment of prognostic markers and outcomes was mainly blinded. Park et al. [21] and Wada et al. [9] did not report blinding. Demchuk et al. [11] and Wada et al. [9] provided the most detailed descriptions of statistical analyses, both reporting accuracy measures for the predictive ability of the spot sign as a pre-specified outcome. One paper reported limited statistical analysis (not including multivariate analysis) [21]. Variables were pre-specified for the multivariate analysis in only 2 papers $[9,11]$. All studies but 1 [21] accounted for the number of patients excluded or dropouts. Only Demchuk et al. [11] reported how missing data were handled.

Regarding prognostic marker assessment, CTA images were obtained in 1 study within $3 \mathrm{~h}$ [9], 3 studies within $6 \mathrm{~h}[11,22,23]$ and in the other 2 studies by $24 \mathrm{~h}$. Only in the study by Wada et al. [9] second-pass images were obtained.

The assessment of HE occurred 1-2 days after haemorrhage onset. The location of the haematoma was reported by all authors but Demchuk et al. [11]. In 2 papers $[10,11]$, radiological outcome was specifically considered the primary outcome.

Table 4 shows reported and/or calculated accuracy measures for the ability of the spot sign in predicting HE. Table 5 shows the effect measures for the ability of the spot sign to predict HE obtained from the $2 \times 2$ contingency tables at univariate analysis.

Results of the multivariate analysis for the same effect measures were reported by Demchuk et al. [11] (relative risk 2.6, 95\% CI 1.8-3.7, including the following parameters in the model: baseline $\mathrm{ICH}$ volume, time from onset to CTA, age $>80$ years, male sex, hypertension, diabetes mellitus, anti-platelet use, anti-coagulation use, systolic blood pressure $>200 \mathrm{~mm} \mathrm{Hg}$, and NIHSS $\geq 18$ ) and Goldstein et al. [10] (odds ratio 18,95\% CI 2.1-162, including age, time to CTA, admission systolic blood pressure and haematoma volume in the model). Table 6 reports accuracy measures for the ability of the spot sign to predict clinical outcomes.

Data from the cohort studied by Wada et al. [9] were obtained from a stacked bar graph reporting percentages 
Table 3. Definition of the spot sign, $\mathrm{HE}$ and clinical outcome across studies

\begin{tabular}{|c|c|c|c|}
\hline Authors & Spot sign/contrast extravasation definition & HE definition & Clinical outcome definition \\
\hline $\begin{array}{l}\text { Demchuk } \\
\text { et al. [11] }\end{array}$ & $\begin{array}{l}\text { Four criteria: (1) serpiginous or spot-like } \\
\text { appearance within the margin of a } \\
\text { parenchymal haematoma without } \\
\text { connection to an outside vessel; ( } 2 \text { ) } \\
\text { contrast density }>1.5 \mathrm{~mm} \text { in diameter in at } \\
\text { least one dimension; (3) contrast density } \\
\text { (Hounsfield units) at least double that of the } \\
\text { background haematoma, and (4) no } \\
\text { hyperdensity at the corresponding } \\
\text { location on non-contrast CT }\end{array}$ & $\begin{array}{l}\text { Substantial HE at follow-up CT } \\
\text { defined as an absolute growth }>6 \mathrm{ml} \\
\text { or relative growth }>33 \% \text { from initial } \\
\text { CT } \\
\text { Other definitions of HE were also } \\
\text { explored as a secondary analysis } \\
\text { because no consensus existed on the } \\
\text { preferred cut-off for clinically } \\
\text { significant HE }\end{array}$ & $\begin{array}{l}\text { (1) Early neurological worsening } \\
\text { ( } \geq 4 \text { points in the NIHSS score at } 24 \mathrm{~h} \\
\text { vs. baseline) } \\
\text { (2) mRS score at } 3 \text { months (median) } \\
\text { (3) Mortality at } 3 \text { months }\end{array}$ \\
\hline $\begin{array}{l}\text { Goldstein } \\
\text { et al. [10] }\end{array}$ & $\begin{array}{l}\text { The presence of contrast extravasation was } \\
\text { operationally defined as the presence of } \\
\text { high-density material within the } \\
\text { hematoma }\end{array}$ & $\begin{array}{l}\text { An increase in volume of }>33 \% \text { from } \\
\text { baseline }\end{array}$ & In-hospital mortality \\
\hline $\begin{array}{l}\mathrm{Li} \\
\text { et al. [22] }\end{array}$ & $\begin{array}{l}\text { On multidetector CTA radiological } \\
\text { criteria: (1) } \geq 1 \text { focus of contrast pooling } \\
\text { within the ICH; (2) with an attenuation } \geq 120 \\
\text { Hounsfield units; ( } 3 \text { ) discontinuous from the } \\
\text { normal or abnormal vasculature } \\
\text { adjacent to the ICH, and (4) of any size and } \\
\text { morphology [3, online] }\end{array}$ & $\begin{array}{l}\text { An increase in hematoma volume } \\
>33 \% \text { or }>12.5 \mathrm{ml} \text { was considered as } \\
\mathrm{HE}\end{array}$ & $\begin{array}{l}\text { (1) In-hospital mortality } \\
\text { (2) Poor outcome at discharge ( } \mathrm{mRS}>2 \text {; } \\
\text { analysed as dichotomised variable, } \\
\text { mRS } 0-2 \text { vs. } 3-6) \\
\text { (3) Mortality at } 3 \text { months } \\
\text { (4) Poor outcome at } 3 \text { months ( } \mathrm{mRS}>2 \text {; } \\
\text { analysed as above) }\end{array}$ \\
\hline $\begin{array}{l}\text { Park } \\
\text { et al. [21] }\end{array}$ & $\begin{array}{l}\text { One or more } 1 \text { - to } 2 \text {-mm-sized foci of } \\
\text { enhancement within the haematoma on axial } \\
\text { view of 3D-CTA source images; an ovoid or } \\
\text { round shape of foci was also included as the } \\
\text { spot sign; the location of the spot sign was } \\
\text { inspected as a centre or peripheries of } \\
\text { haematoma }\end{array}$ & $\begin{array}{l}\text { An increase in volume }>30 \% \text { or }>6 \mathrm{ml} \\
\text { from the baseline brain CT scan by } \\
\text { the criteria of Wada et al. [9] }\end{array}$ & $\begin{array}{l}\text { (1) Mortality at } 3 \text { months } \\
\text { [(2) Clinical deterioration; accuracy } \\
\text { measures neither reported nor } \\
\text { calculable] }\end{array}$ \\
\hline $\begin{array}{l}\text { Rodriguez- } \\
\text { Luna } \\
\text { et al. [23] }\end{array}$ & Definition not provided in the Methods & $\begin{array}{l}\text { Ultra-early haematoma growth } \\
\text { (defined as the relation between } \\
\text { baseline ICH volume and onset- } \\
\text { imaging time) and haematoma } \\
\text { growth (defined as haematoma } \\
\text { enlargement }>33 \% \text { or }>6 \mathrm{ml} \text { at } 24 \mathrm{~h} \text { ) }\end{array}$ & $\begin{array}{l}\text { (1) Early neurological; increase of } \geq 4 \\
\text { points in the NIHSS score or death } 24 \mathrm{~h} \\
\text { after symptom onset } \\
\text { (2) Poor long-term outcome ( } \mathrm{mRS}>2 \text { at } \\
3 \text { months) } \\
\text { (3) Mortality at } 3 \text { months }\end{array}$ \\
\hline $\begin{array}{l}\text { Wada } \\
\text { et al. [9] }\end{array}$ & $\begin{array}{l}\text { One or more } 1 \text { - to } 2-\mathrm{mm} \text { foci of } \\
\text { enhancement within the haematoma on CTA } \\
\text { source images } \\
\text { Spot location within the haematoma and the } \\
\text { number of spots were noted } \\
\text { Extravasation was defined as enlargement of } \\
\text { the contrast density on the immediately } \\
\text { proceeding enhanced CT }\end{array}$ & $\begin{array}{l}\text { An increase in hematoma size }>30 \% \\
\text { or }>6 \mathrm{ml} \text { considered significant } \\
\text { enlargement }\end{array}$ & $\begin{array}{l}\text { (1) In-hospital mortality } \\
\text { (2) mRS }(0-2,3-5,6) \text { at } 3 \text { months }\end{array}$ \\
\hline
\end{tabular}

Table 4. Calculated odds ratio (OR) with 95\% CI for HE prediction by the spot sign

\begin{tabular}{lcc}
\hline Authors & OR & $95 \%$ CI \\
\hline Demchuk et al. [11] & 5.61 & $2.98-10.56$ \\
Goldstein et al. [10] & 13 & $1.63-103.58$ \\
Li et al. [22] & 36.51 & $12.31-108.23$ \\
Park et al. [21] & 15.75 & $4.63-53.49$ \\
Rodriguez-Luna et al. [23] & 3.33 & $0.93-11.94$ \\
Wada et al. [9] & 83.33 & $7.72-899.59$ \\
\hline
\end{tabular}

of patients with mRS scores of $0-2,3-5$ and 6 , according to the presence or absence of the spot sign.

A number of items on our data extraction form were not available in any, or the majority, of the studies, e.g. prognostic marker data, data on CTA time from admission, second-pass CTA images, number of spot signs, maximum axial dimension and maximum attenuation.

A funnel plot was drawn and visual assessment suggests some possibility of publication bias (see online suppl. appendix 4). 
Table 5. Clinical outcomes

\begin{tabular}{|c|c|c|c|c|c|c|c|c|}
\hline Outcome/authors & $\begin{array}{l}\text { Prevalence, } \\
\mathrm{n} / \text { total } \\
(95 \% \mathrm{CI})\end{array}$ & $\begin{array}{l}\text { Sensitivity, } \\
\% \\
(95 \% \text { CI })\end{array}$ & $\begin{array}{l}\text { Specificity, } \\
\% \\
(95 \% \text { CI })\end{array}$ & $\begin{array}{l}\text { Positive } \\
\text { predictive } \\
\text { value, \% } \\
(95 \% \mathrm{CI})\end{array}$ & $\begin{array}{l}\text { Negative } \\
\text { predictive } \\
\text { value, \% } \\
(95 \% \mathrm{CI})\end{array}$ & $\begin{array}{l}\text { Positive } \\
\text { likelihood ratio } \\
(95 \% \mathrm{CI})\end{array}$ & $\begin{array}{l}\text { Negative } \\
\text { likelihood ratio } \\
(95 \% \mathrm{CI})\end{array}$ & $\begin{array}{l}\text { Accuracy, } \\
\%\end{array}$ \\
\hline
\end{tabular}

Early clinical deterioration

Demchuk et al. [11]

Rodriguez-Luna et al. [23]

Poor outcome at discharge

Li et al. [22]

Goldstein et al. [10]

Li et al. [22]

Three-month mortality

Demchuk et al. [11]

Li et al. [22]

Park et al. [21]

$36 / 192(19 \%)(14-25) \quad 47(31-64) \quad 77(69-83) \quad 32(20-46)$

$86(79-91) \quad 2.05(1.31-3.21) \quad 0.69(0.5-0.94) \quad 71$

$18 / 89(20 \%)(13-30) \quad 50(27-73) \quad 89(78-95) \quad 53(28-76) \quad 88(77-94) \quad 4.44(1.99-9.87) \quad 0.56(0.35-0.9) \quad 81$

$103 / 139(74 \%)(66-81) \quad 26.2(18-36) \quad 91.7(74-98) \quad 90(72-97) \quad 30.3(22-40) \quad 3.15(1.02-9.75) \quad 0.80(0.71-0.91) \quad 43$

$26 / 104(25 \%)(17-35) \quad 73(52-88) \quad 50(39-61) \quad 32(21-93) \quad 85(71-93) \quad 1.46(1.06-2.02) \quad 0.54(0.28-1.04) \quad 56$

$10 / 139(7 \%)(4-13) \quad 60(27-86) \quad 81.4(73-87) \quad 20(8-39) \quad 96.3(90-99) \quad 3.23(1.73-6) \quad 0.49(0.23-1.05) \quad 80$

Rodriguez-Luna et al. [23]

Wada et al. [9]

Poor outcome at 3 months

Li et al. [22]

Rodriguez-Luna et al. [23]

Wada et al. [9]

$54 / 211(26 \%)(20-32)$

$16 / 139(12 \%)(7-18)$

20/110 (18\%) (12-27)

$16 / 89$ (18\%) (11-28)

$7 / 39(18 \%)(8-34)$

$72 / 139(52 \%)(43-60) \quad 36.1(25-48)$

$15 / 89$ (17\%) (1-27)

$43(30-57) \quad 81(74-87) \quad 43(30-58) \quad 80(73-86) 2.23(1.43-3.48)$

$50(26-74) \quad 82.1(74-88) 26.7(13-46) \quad 92.7(86-97) \quad 2.8(1.5-5.19)$

$40(20-64) \quad 88(79-93) \quad 42(21-66) \quad 87(78-93) \quad 3.27(1.51-7.08)$

$36(16-64) \quad 85(74-92) \quad 35(15-61)$

$43(12-80) \quad 69(50-83) \quad 23(6-54)$

$86(75-93) 2.49(1.2-5.73)$

$85(64-95) 1.37(0.51-3.72)$

$0.71(0.56-0.9) \quad 71$

$0.61(0.37-1) \quad 78$

$0.68(0.48-0.98) \quad 79$

$0.74(0.5-1.1) \quad 76$

$0.83(0.43-1.62) \quad 64$

$22 / 39(56 \%)(40-72)$
$27(9-55)$

$41(21-63)$
94 (85-98) 86.7 (68-96) 57.8

$82(71-90) \quad 24(8-50)$

$69(39-90)$
$6.8(48-67) 6.05(2.23-16.42) \quad 0.68(0.57-0.81) \quad 64$

$85(74-92) \quad 1.52(0.57-4.02) \quad 0.89(0.65-1.21) \quad 73$

$50(30-70) \quad 1.74(0.64-4.69) \quad 0.77(0.53-1.13) \quad 56$

Table 6. Radiological outcome: accuracy measures for the spot sign in predicting HE

\begin{tabular}{|c|c|c|c|c|c|c|c|c|}
\hline Authors & $\begin{array}{l}\text { Prevalence, } \\
\text { n/total } \\
(95 \% \mathrm{CI})\end{array}$ & $\begin{array}{l}\text { Sensitivity, } \\
\% \\
(95 \% \text { CI })\end{array}$ & $\begin{array}{l}\text { Specificity, } \\
\% \\
(95 \% \text { CI })\end{array}$ & $\begin{array}{l}\text { Positive } \\
\text { predictive } \\
\text { value, } \% \\
(95 \% \mathrm{CI})\end{array}$ & $\begin{array}{l}\text { Negative } \\
\text { predictive } \\
\text { value, } \% \\
(95 \% \mathrm{CI})\end{array}$ & $\begin{array}{l}\text { Positive } \\
\text { likelihood ratio } \\
(95 \% \mathrm{CI})\end{array}$ & $\begin{array}{l}\text { Negative } \\
\text { likelihood ratio } \\
(95 \% \mathrm{CI})\end{array}$ & $\begin{array}{l}\text { Accuracy, } \\
\%\end{array}$ \\
\hline Demchuk et al. [11] & $73 / 228(32 \%)(26-39)$ & $51(39-62)$ & $85(78-90)$ & $61(47-73)$ & $78(71-84)$ & $3.27(2.13-5.04)$ & $0.58(0.46-0.74)$ & 74 \\
\hline Goldstein et al. [10] & $14 / 104(13 \%)(8-22)$ & $93(64-100)$ & $50(39-61)$ & $22(13-36)$ & $98(87-100)$ & $1.86(1.44-2.39)$ & $0.14(0.02-0.97)$ & 56 \\
\hline Li et al. [22] & $32 / 139(23 \%)(16-31)$ & $72(53-86)$ & $93(87-97)$ & 77 (57-89) & $92(84-96)$ & $10.99(5.2-23.22)$ & $0.30(0.17-0.52)$ & 88 \\
\hline Park et al. [21] & $16 / 110(15 \%)(9-23)$ & $63(36-84)$ & $90(82-95)$ & $53(29-75)$ & $93(86-97)$ & $6.53(3.15-13.52)$ & $0.41(0.22-0.78)$ & 86 \\
\hline Rodriguez-Luna et al. [23] & $13 / 89(15 \%)(8-24)$ & $38(15-68)$ & $84(74-91)$ & $29(11-56)$ & $89(79-95)$ & $2.44(1.03-5.77)$ & $0.73(0.47-1.13)$ & 78 \\
\hline Wada et al. [9] & $11 / 39(28 \%)(16-45)$ & $91(62-100)$ & $89(72-96)$ & $77(50-92)$ & $96(81-99)$ & $8.50(2.9-25)$ & $0.10(0.02-0.7)$ & 90 \\
\hline
\end{tabular}

The variation in odds ratios attributable to heterogeneity was very high $\left(\mathrm{I}^{2}=94.0 \%\right)$ in an exploratory test for heterogeneity for the radiological outcome.

\section{Discussion}

\section{Summary of Evidence}

The systematic review identified 6 cohort studies fulfilling our inclusion and exclusion criteria. Although each study reported an association of the spot sign with $\mathrm{HE}$ and poor clinical outcome, the accuracy of this association overall was not measurable, leaving our research question unanswered.

Studies may not be comparable for several reasons. Firstly, the study design was inconsistent. In particular, the retrospective study by Goldstein et al. [10] could have introduced a selection bias, since patients who underwent CTA were able to be included later depending on the treating physician's decision. Similarly, Rodriguez-Luna et al. [23] did not report the reasons why only a subset of patients underwent CTA. 
The most striking feature of the selected studies is the use of different definitions, not only for the spot sign, but also for radiological and clinical outcomes.

The presence of contrast extravasation within the haematoma on CTA imaging has been differently classified across studies. Some studies used strictly defined radiological and morphological criteria [11,21, 22], 1 study did not report any definition [23], and only 1 study differentiated between the terms 'spot sign' and 'contrast extravasation' when the focus of enhancement was seen on CTA source images or on CT images following contrast enhancement, respectively [9]. Since the presence of contrast extravasation might be more sensitive than the presence of the spot sign [19], those terms should not be used interchangeably, especially without specifying the acquisition technique. Lastly, a 'spot sign score' was developed [24] and used in only 1 of the selected papers [22]. In a recently published analysis from the PREDICT study [25], the spot sign score independently predicted HE; however, one of its components alone, the spot number, could improve risk stratification of this event. Furthermore, the pathophysiology of the spot sign is still unclear but could involve a progressive small vessel damage following ICH, as first proposed by Fisher [26] and suggested by a recent study, introducing yet another radiological marker, the 'tail sign', to indicate bleeding in a striate artery in putaminal ICH [27].

HE was also defined differently across studies, using relative (e.g. $>30$ or $33 \%$ ) or absolute change (e.g. mostly $\geq 6$ or $\geq 12.5 \mathrm{ml}$ ) in haematoma volume on follow-up CT. The PREDICT study by Demchuk et al. [11] demonstrated that different cut-offs for absolute or relative changes in haematoma volume may not affect the predictive value of HE.

The variety in clinical outcomes is susceptible to outcome reporting bias. Furthermore, definition and analysis of disability (measured with mRS) were often unclear and suboptimal, confirming a recognised limitation of stroke trials [28]. This might be the main limitation of all the selected studies. Indeed, evidence from trials and related meta-analyses investigating recombinant factor VIIa in the setting of spontaneous ICH $[29,30]$ showed that reducing or even stopping haematoma growth does not necessarily correspond to improving clinical outcome. Although such a result could be explained by inappropriate patient selection, it underlines the importance of identifying appropriate clinical outcomes to reflect expected effects of interventions.

Other quality-related issues could have affected the results. In particular, a sample size calculation was re- ported by only two groups, with studies potentially being underpowered. Almost no study reported $95 \%$ CI of accuracy measures, which should be done for any binomial proportion. When calculated, CI were wide, reflecting relatively small studies. Finally, the choice of candidate variables for univariate and multivariate analyses was not always comprehensive. Ideally, all proposed HE determinants, such as initial haematoma volume [31], time from onset to imaging [32], presence of previous white matter lesions [33,34], haemorrhage location [35] and presence of cerebral atrophy, the latter independently associated with poor outcome [36], should be included not only for the radiological outcome but also for the clinical outcome.

A risk of bias is also suggested from the funnel plot (online suppl. appendix 4). Given the paucity of studies, only a visual assessment of the direction and distribution of the effect measures of each study on the funnel plot was carried out [17]. Asymmetry could arise from publication bias, since all selected studies reported positive results, poor choice of effect measure or chance. Furthermore, our literature search only identified English language studies, with a potential language bias. In any case, the relatively high variability in the accuracy measures of the spot sign across studies can undermine its role as a prognostic marker $[12,37]$. When used for patient selection, a prognostic marker should ideally have a high specificity to minimise the risk of excluding patients who could still benefit from a potentially useful intervention. On the other hand, its use could unnecessarily include patients who have been wrongly recognised as at risk on the basis of a misjudgement of the presence of the spot sign. In this respect, Gazzola et al. [20] reported on spot sign mimics, such as calcifications or pseudo-aneurysms in the setting of tumours, arteriovenous malformations or moyamoya syndrome.

\section{Strengths and Limitations}

The present systematic review used recognised standardised methods to search, identify and evaluate eligible studies. However, it has some limitations. Authors were not contacted to obtain the original data for each of the eligible studies, which might have minimised any reporting bias. Furthermore, quality assessment was conducted using a novel tool based on recommendations for tumour marker prognostic studies. Although belonging to a different field, those recommendations had been used by other authors systematically investigating prognostic markers in ischemic stroke [38] and are consistent with expert opinions in the field [39]. 


\section{Conclusions}

In summary, there is no gold standard for the prediction of haematoma growth and poor clinical outcome in spontaneous ICH. Despite its promising performance in single studies, the high variability found in this systematic review does not allow us to conclude that the CTA spot sign is currently a valid prognostic marker, which is in line with the AHA/ASA 2010 recommendations [40]. Incorporating the CTA spot sign in a clinical prediction score including predictors of $\mathrm{HE}$ and taking into account oral anti-coagulant agent use could improve the accuracy of risk stratification [41]. Recently, some studies propose a 'dynamic spot sign' using CT perfusion, a quantitative technique which allows a real-time contrast extravasation measurement. The dynamic spot sign seems to be a better prognostic marker than the CTA spot sign with higher sensitivity and predictive value [42-44], however, it needs to be standardised and validated.
In conclusion, further appropriately powered studies, using the best available technique, standardised marker and outcome definitions, and potential combination with other relevant predictors of $\mathrm{HE}$ and poor outcome are required before translating study results into clinical practice.

\section{Acknowledgements}

We acknowledge Dr. Gabriele Menzel (librarian, Charité University, Berlin) for her assistance in the literature search.

\section{Disclosure Statement}

Angela Del Giudice, Delia D’Amico, Jan Sobesky and Ian Wellwood declare no conflicts of interest.

\section{References}

$\checkmark 1$ Feigin VL, Lawes CMM, Bennett DA, BarkerCollo SL, Parag V: Worldwide stroke incidence and early case fatality reported in 56 population-based studies: a systematic review. Lancet Neurol 2009;8:355-369.

$\longrightarrow 2$ Van Asch CJ, Luitse MJ, Rinkel GJ, Van der Tweel I, Algra A, Klijn CJ: Incidence, case fatality, and functional outcome of intracerebral haemorrhage over time, according to age, sex, and ethnic origin: a systematic review and meta-analysis. Lancet Neurol 2010;9:167176.

-3 Davis SM, Broderick J, Hennerici M, Brun NC, Diringer MN, Mayer SA, et al: Hematoma growth is a determinant of mortality and poor outcome after intracerebral hemorrhage. Neurology 2006;66:1175-1181.

4 Dowlatshahi D, Demchuk AM, Flaherty ML, Ali M, Lyden PL, Smith EE: Defining hematoma expansion in intracerebral hemorrhage: relationship with patient outcomes. Neurology 2011;76:1238-1244.

5 Steiner T, Bösel J: Options to restrict hematoma expansion after spontaneous intracerebral hemorrhage. Stroke 2010;41:402-409.

6 Brouwers HB, Greenberg SM: Hematoma expansion following acute intracerebral hemorrhage. Cerebrovasc Dis 2013;35:195-201.

7 Becker KJ, Baxter AB, Bybee HM, Tirschwell DL, Abouelsaad T, Cohen WA: Extravasation of radiographic contrast is an independent predictor of death in primary intracerebral haemorrhage. Stroke 1999;30:2025-2032.

$\rightarrow 8$ Murai Y, Takagi R, Ikeda Y, Yamamoto Y, Teramoto A: Three-dimensional computerized tomography angiography in patients with hyperacute intracerebral haemorrhage. J 16 McShane LM, Altman DG, Sauerbrei W, Neurosurg 1999;91:424-431.

-9 Wada R, Aviv RI, Fox AJ, Sahlas DJ, Gladstone DJ, Tomlinson G, et al: CT angiography 'spot sign' predicts haematoma expansion in acute intracerebral haemorrhage. Stroke 2007;38:1257-1262.

10 Goldstein JN, Fazen LE, Snider R, Schwab K, Greenberg SM, Smith EE, et al: Contrast extravasation on CT angiography predicts hematoma expansion in intracerebral hemorrhage. Neurology 2007;68:889-894.

11 Demchuk AM, Dowlatshahi D, Rodriguezluna D, Molina CA, Blas YS, Dzialowski I, et al: Prediction of haematoma growth and outcome in patients with intracerebral haemorrhage using the CT-angiography spot sign (PREDICT): a prospective observational study. Lancet Neurol 2012;4422:1-8.

12 Wardlaw JM: Prediction of haematoma expansion with the CTA spot sign: a useful bio- 20 marker? Lancet Neurol 2012;11:294-295.

$\checkmark 13$ Adams HP, Davis PH, Leira EC, Chang KC, Bendixen BH, Clarke WR, et al: Baseline NIH Stroke Scale score strongly predicts outcome after stroke: a report of the Trial of Org 10172 in Acute Stroke Treatment (TOAST). Neurology 1999;53:126-131.

14 De Haan R, Limburg M, Bossuyt P, Van der Meulen J, Aaronson N: The clinical meaning of Rankin 'handicap' grades after stroke. Stroke 1995;26:2027-2030.

15 Hayden JA, Côté P, Bombardier C: Evaluation of the quality of prognosis studies in systematic reviews. Ann Intern Med 2006;144:427437. Taube SE, Gion M, Clark GM; Statistics Subcommittee of the NCI-EORTC Working Group on Cancer Diagnostics: Reporting recommendations for tumor marker prognostic studies (REMARK). J Natl Cancer Inst 2005; 97:1180-1184.

17 Song F, Khan KS, Dinnes J, Sutton AJ: Asymmetric funnel plots and publication bias in meta-analyses of diagnostic accuracy. Int J Epidemiol 2002;31:88-95.

18 Kent DM, Rothwell PM, Ioannidis JPA, Altman DG, Hayward RA: Assessing and reporting heterogeneity in treatment effects in clinical trials: a proposal. Trials 2010;11:85.

19 Hallevi H, Abraham AT, Barreto AD, Grotta JC, Savitz SI: The spot sign in intracerebral hemorrhage: the importance of looking for contrast extravasation. Cerebrovasc Dis 2010; 29:217-220.

20 Gazzola S, Aviv RI, Gladstone DJ, Mallia G, Li V, Fox AJ, et al: Vascular and nonvascular mimics of the CT angiography 'spot sign' in patients with secondary intracerebral hemorrhage. Stroke 2008;39:1177-1183.

21 Park SY, Kong MH, Kim JH, Kang DS, Song KY, Huh SK: Role of 'spot sign' on CT angiography to predict hematoma expansion in spontaneous intracerebral hemorrhage. J Korean Neurosurg Soc 2010;48:399-405.

22 Li N, Wang Y, Wang W, Ma L, Xue J, Weissenborn $\mathrm{K}$, et al: Contrast extravasation on computed tomography angiography predicts clinical outcome in primary intracerebral hemorrhage: a prospective study of 139 cases. Stroke 2011;42:3441-3446. 
-23 Rodriguez-Luna D, Rubiera M, Ribo M, Coscojuela P, Pineiro S, Hernandez-Guillamon $\mathrm{M}$, et al: Ultraearly hematoma growth predicts poor outcome after acute intracerebral hemorrhage. Neurology 2012;77:15991604.

24 Delgado Almandoz JE, Yoo AJ, Stone MJ, Schaefer PW, Oleinik A, Brouwers HB, et al: The spot sign score in primary intracerebral hemorrhage identifies patients at highest risk of in-hospital mortality and poor outcome among survivors. Stroke 2010;41:54-60.

25 Huynh TJ, Demchuk AM, Dowlatshahi D, Gladstone DJ, Krischek O, Kiss A, et al: Spot sign number is the most important spot sign characteristic for predicting hematoma expansion using first-pass computed tomography angiography: analysis from the PREDICT study. Stroke 2013;44:972-977.

26 Fisher CM: Pathological observations in hypertensive cerebral hemorrhage. J Neuropathol Exp Neurol 1971;30:536-550.

-27 Sorimachi T, Osada T, Baba T, Inoue G, Atsumi $\mathrm{H}$, Ishizaka $\mathrm{H}$, et al: The striate artery, hematoma, and spot sign on coronal images of computed tomography angiography in putaminal intracerebral hemorrhage. Stroke 2013;44:1830-1832.

28 Bath PMW, Lees KR, Schellinger PD, Altman $\mathrm{H}$, Bland M, Hogg C, et al: Statistical analysis of the primary outcome in acute stroke trials. Stroke 2012;43:1171-1178.

-29 Al-Shahi Salman R: Haemostatic drug therapies for acute spontaneous intracerebral haemorrhage. Cochrane Database Syst Rev 2009;4:CD005951.
30 Yuan ZH, Jiang JK, Huang WD, Pan J, Zhu JY, Wang JZ: A meta-analysis of the efficacy and safety of recombinant activated factor VII for patients with acute intracerebral hemorrhage without hemophilia. J Clin Neurosci 2010;17: 685-693.

31 Broderick JP, Brott TG, Duldner JE, Tomsick T, Huster G: Volume of intracerebral haemorrhage. A powerful and easy-to-use predictor of 30-day mortality. Stroke 1993;24:987993.

32 Brouwers HB, Falcone GJ, McNamara KA, Ayres AM, Oleinik A, Schwab K, et al: CTA spot sign predicts hematoma expansion in patients with delayed presentation after intracerebral hemorrhage. Neurocrit Care 2012;17: 421-428.

33 Lou M, Al-Hazzani A, Goddeau RP, Novak V, Selim M: Relationship between white-matter hyperintensities and hematoma volume and growth in patients with intracerebral hemorrhage. Stroke 2010;41:34-40.

34 Caprio FZ, Maas MB, Rosenberg NF, Kosteva AR, Bernstein RA, Alberts MJ, et al: Leukoaraiosis on magnetic resonance imaging correlates with worse outcomes after spontaneous intracerebral hemorrhage. Stroke 2013; 44:642-646.

35 Moussouttas M, Malhotra R, Fernandez L, Maltenfort M, Holowecki M, Delgado J, et al: Impact of intraventricular hemorrhage upon intracerebral hematoma expansion. Neurocrit Care 2011;14:50-54.

36 Herweh C, Prager E, Sykora M, Bendszus M: Cerebral atrophy is an independent risk factor for unfavorable outcome after spontaneous supratentorial intracerebral hemorrhage. Stroke 2013;44:968-971.

- 37 Brouwers HB, Goldstein JN, Romero JM, Rosand J: Clinical applications of the computed tomography angiography spot sign in acute intracerebral hemorrhage: a review. Stroke 2012;43:3427-3432.
38 Whiteley W, Chong WL, Sengupta A, Sandercock P: Blood markers for the prognosis of ischemic stroke: a systematic review. Stroke 2009;40:e380-e389.

39 Altman DG: Systematic reviews in health care: systematic reviews of evaluations of prognostic variables. BMJ 2001;323:224-228.

40 Morgenstern LB, Hemphill JC, Anderson C, Becker K, Broderick JP, Connolly ES, et al: Guidelines for the management of spontaneous intracerebral hemorrhage: a guideline for healthcare professionals from the American Heart Association/American Stroke Association. Stroke 2010;41:2108-2129.

41 Brouwers HB, Chang Y, Falcone GJ, Cai X, Ayres AM, Battey TWK, Vashkevich A, McNamara KA, Valant V, Schwab K, Orzell SC, Bresette LM, Feske SK, Rost NS, Romero JM, Viswanathan A, Chou SHY, Greenberg S, Rosand J, Goldstein JN: Predicting hematoma expansion after primary intracerebral hemorrhage. JAMA 2014;71:158-164.

42 d'Esterre CD, Chia TL, Jairath A, Lee TY, Symons SP, Aviv RI: Early rate of contrast extravasation in patients with intracerebral hemorrhage. AJNR Am J Neuroradiol 2011; 32:1879-1884

43 Sun S-J, Gao P-Y, Sui B-B, Hou X-Y, Lin Y, Xue J, et al: 'Dynamic spot sign' on CT perfusion source images predicts haematoma expansion in acute intracerebral haemorrhage. Eur Radiol 2013;23:1846-1854.

44 Koculym A, Huynh TJ, Jakubovic R, Zhang L, Aviv RI: CT perfusion spot sign improves sensitivity for prediction of outcome compared with CTA and postcontrast CT. AJNR Am J Neuroradiol 2013;34:965-970, S1. 